\title{
La naturaleza jurídica de los mandatos de interconexión de redes de telecomunicaciones y el cambio de posición de OSIPTEL
}

\author{
Andrea Morelli Ferreyros* \\ Luis Fernando Roca Lizarzaburu*
}

Resumen. - El marco normativo de las telecomunicaciones otorga a OSIPTEL -en calidad de regulador- la facultad de emitir mandatos de interconexión que obligan a las empresas operadoras a dar acceso a sus redes y permitir que estas se interconecten con otras redes de telecomunicaciones. Según este marco normativo, OSIPTEL emite los mandatos de interconexión en ejercicio de su "función normativa". Sin embargo, ¿significa esto que los mandatos de interconexión son normas? ¿La función normativa que OSIPTEL ejerce al emitir un mandato de interconexión, determina la naturaleza jurídica de este acto? En este artículo, los autores analizan la referida figura a la luz de la doctrina y jurisprudencia de los actos y reglamentos administrativos, haciendo especial énfasis en la forma de impugnación de los mandatos y el reciente cambio de posición de OSIPTEL respecto de su impugnación en la vía judicial.

\begin{abstract}
The regulatory framework for telecommunications gives OSIPTEL [in its capacity as a regulatory body the power to issue interconnection mandates requiring operators to give access to their networks and to allow them to interconnect with other telecommunications networks. According to this regulatory framework, OSIPTEL issues the above-mentioned interconnection mandates in the exercise of its regulatory function. However, does this mean that interconnection mandates are rules? Does the regulatory function that OSIPTEL performs when issuing an interconnection mandate determine the legal nature of this act? In this article, the authors analyze the mentioned figure in the light of the doctrine and jurisprudence of administrative acts and regulations, with particular emphasis on the form of challenges to mandates and the recent change in OSIPTEL's position with regard to judicial challenges to mandates.
\end{abstract}

\section{Palabras claves. - OSIPTEL - Telecomunicaciones- Acto administrativo}

Keywords. - OSIPTEL - Telecommunications- Administrative act

* Agradecemos especialmente a la Dra. María del Rosario Quiroga, por sus valiosas contribuciones en las reflexiones contenidas en el presente artículo

* Abogada. Asociada del área de Regulación de Servicios Públicos e Infraestructura del Estudio Rodrigo, Elías \& Medrano.

* Abogado. Asociado del área de Regulación de Servicios Públicos e Infraestructura del Estudio Rodrigo, Elías \& Medrano. 



\section{Introducción}

El proceso de privatización de las telecomunicaciones en el Perú, y su posterior apertura al mercado, han permitido que hoy exista competencia en la prestación de los servicios públicos de telecomunicaciones, especialmente en el mercado de servicios móviles en el cual los usuarios cada vez cuentan con más y mejores opciones para estar conectados.

El marco regulatorio de interconexión ha cumplido un rol fundamental en la generación de esa competencia. La interconexión permite que las redes de las distintas empresas operadoras se conecten y, por lo tanto, que los usuarios de una red puedan acceder a otras redes y a los servicios que las operadoras prestan sobre éstas. Esta integración de redes y servicios es la que con mayor énfasis ha contribuido a generar competencia en el sector, por lo que su importancia para el correcto funcionamiento del mercado, el desarrollo de los servicios de telecomunicaciones y de nuevas tecnologías, es inobjetable.

La importancia de la interconexión de las redes de telecomunicaciones está reflejada en nuestro marco legal a lo largo de varias disposiciones. Así, tenemos que el Texto Único Ordenado de Ley de Telecomunicaciones1 (la "Ley de Telecomunicaciones"), en su artículo $7^{\circ}$, establece que "la interconexión de las redes y los servicios públicos de telecomunicaciones es de interés público y social".

En el mismo sentido, el artículo $103^{\circ}$ del Texto Único Ordenado del Reglamento de la Ley de Telecomunicaciones2 (el "Reglamento de la Ley de Telecomunicaciones") establece que la interconexión "es de interés público y social y, por tanto, es obligatoria. Además, señala que la "la interconexión es una condición esencial de la concesión" (el énfasis en negritas es agregado).

El numeral 37 de los Lineamientos de Apertura del Mercado de Servicios de Telecomunicaciones3, describe a la interconexión como "un elemento clave para el éxito de un proceso de apertura del mercado de telecomunicaciones". La misma norma señala que "la predeterminación de los aspectos relevantes de la interconexión resulta esencial para promover la entrada rápido de nuevos operadores al mercado", señalando a continuación que si tales parámetros no son definidos "la entrada de operadores se vería afectada por incertidumbre e inestabilidad".

Finalmente, el artículo $105^{\circ}$ del Reglamento de Telecomunicaciones agrega que, en virtud del principio de igualdad de acceso, los operadores de servicios públicos de

Texto Único Ordenado de la Ley de Telecomunicaciones, aprobado mediante Decreto Supremo 13-93-TCC.

2 Texto Único Ordenado del Reglamento de Ley de Telecomunicaciones, aprobado mediante Decreto Supremo 020-2007-MTC.

3 Aprobados mediante Decreto Supremo 020-98-MTC. 
telecomunicaciones están obligados a interconectarse, acordando los aspectos técnicos, económicos, tarifarios y de mercado, en condiciones de igualdad.

La relevancia que tiene la interconexión para la competencia en el mercado y el hecho de que las empresas que ya operan en éste tienen poco o ningún interés en dar acceso y/o compartir su infraestructura con nuevos operadores, justifica la intervención del Estado no solo para establecer la obligación legal de las empresas operadoras de interconectarse, sino para regular la interconexión, normando, entre otros, los mecanismos para la negociación y establecimiento de la interconexión entre operadoras. Uno de estos mecanismos es el mandato de interconexión.

Al respecto, el Texto Único Ordenado de las Normas de Interconexión4 (las “Normas de Interconexión") permite que, vencido el plazo aplicable para que dos operadoras acuerden los términos y condiciones aplicables a la interconexión que una de ellas ha pedido a la otra, cualquiera de los dos pueda solicitar a OSIPTEL la emisión de un mandato. Este mandato, según señalan las Normas de Interconexión, contendrá las especificaciones técnicas, legales y económicas que regirán la relación de interconexión entre las empresas operadoras.

La interconexión, entonces, no es una herramienta de regulación menor. Es un instrumento fundamental para generar y mantener la competencia en el mercado, objetivo que se logra principalmente a través del establecimiento de derechos y obligaciones para las empresas operadoras que intervienen en la relación de interconexión o que son ajenas a ésta, pero que tienen un legítimo interés sobre algunos aspectos de dicha interconexión.

Siendo el mandato un instrumento legal tan relevante en la esfera jurídica de las empresas operadoras, y para la competencia y desarrollo del mercado de las telecomunicaciones, es necesario tener claridad respecto de la naturaleza jurídica de esta figura. Ello debido a que solo a partir de esta definición podrá comprenderse los efectos que tienen los mandatos de interconexión sobre los distintos agentes del mercado y la vía legal para cuestionarlos en los casos en que resulte necesario.

Dicho lo anterior, el presente trabajo analizará la naturaleza jurídica de los mandatos de interconexión emitidos por OSIPTEL para definir si estos constituyen normas o actos administrativos y el fuero al que corresponde acudir una vez agotada la vía administrativa en OSIPTEL.

Esta definición es hoy más importante que nunca, dado el radical cambio de posición de OSIPTEL en torno a la clasificación de los mandatos. En efecto, en los últimos dos años hemos notado que OSIPTEL vienen sosteniendo que los mandatos son normas porque, de acuerdo con el marco legal, se emiten en ejercicio de la función normativa; en consecuencia, una vez agotada la vía administrativa,

Aprobado mediante Resolución 134-2012-CD-OSIPTEL.

Artículo $52^{\circ}$ de las Normas de Interconexión. 
su cuestionamiento corresponde ser tramitado a través un proceso de acción popular.

En nuestra opinión, OSIPTEL se equivoca. En este artículo postulamos que los mandatos no son normas, sino actos administrativos y que esta calificación jurídica no se ve alterada por el hecho de que OSIPTEL, conforme a lo dispuesto en el marco legal, emita los mandatos en ejercicio de su función normativa.

\section{La facultad de OSIPTEL de emitir mandatos de interconexión}

Empecemos por referirnos a la facultad de OSIPTEL para emitir los mandatos. El artículo $3^{\circ}$ de la Ley 27332, Ley Marco de Organismos Reguladores de la Inversión Privada en los Servicios Públicos (la "Ley 27332"), establece que tales organismos ejercen diversas funciones, dentro de las cuales se encuentran las funciones normativa; supervisora; reguladora; fiscalizadora y sancionadora; de solución de controversias; y, de solución de reclamos de usuarios. Para el propósito de este trabajo, nos referiremos solo a la función normativa de OSIPTEL.

El referido artículo $3^{\circ}$ describe la función normativa que ejerce OSIPTEL, de la siguiente manera:

"Función normativa: comprende la facultad exclusiva de dictar, en el ámbito y en materia de sus respectivas competencias, los reglamentos, normas de carácter general y mandatos $\mathbf{u}$ otras normas de carácter particular referidas a intereses, obligaciones o derechos de las entidades o actividades supervisadas o de sus usuarios".

Como se aprecia, la Ley 27332 señala que los mandatos son emitidos por los organismos reguladores en ejercicio de su función normativa. Esta misma disposición ha sido recogida en la normativa de telecomunicaciones. Así, tenemos que el Reglamento General de OSIPTEL6 (el "Reglamento de OSIPTEL"), en su artículo $23^{\circ}$, establece que la función normativa de OSIPTEL comprende la facultad de dictar mandatos7. Lo misma referencia existe en los considerandos de las Normas de Interconexións.

Entonces, ciñéndonos a lo establecido en la normativa aplicable, es claro que los mandatos de interconexión que expide OSIPTEL son emitidos en ejercicio de la función normativa que el marco legal le ha atribuido. ¿Quiere decir esto que los mandatos de interconexión que emite OSIPTEL son normas? ¿Cuál es la naturaleza

\footnotetext{
Aprobado mediante Decreto Supremo 008-2001-PCM.

“Artículo 23- Definición de Función Normativa. (...) Asimismo, comprende la facultad de dictar mandatos y normas de carácter particular; referidas a intereses, obligaciones o derechos de las entidades o actividades bajo su competencia, o de sus usuarios".

8 “(...) el Organismo Supervisor de Inversión Privada en Telecomunicaciones (OSIPTEL) ejerce, entre otras, la función normativa que comprende la facultad de dictar en el ámbito y en materia de sus respectivas competencias, los reglamentos, normas que regulen los procedimientos a su cargo, otras de carácter general y mandatos u otras normas de carácter particular referidas a intereses, obligaciones o derechos de las entidades o actividades supervisadas o de sus usuarios".
} 
jurídica del mandato? ¿Es una norma o un acto administrativo? Dedicamos el siguiente capítulo a analizar esta cuestión.

\section{El mandato de interconexión: ¿Acto administrativo norma?}

Mucho se ha escrito en el ámbito del Derecho Administrativo acerca de la diferencia entre actos administrativos y normas administrativas. A continuación, se describen las principales características atribuidas por la doctrina y la jurisprudencia a los actos administrativos y los reglamentos (o normas administrativas) para, posteriormente, analizar a qué categoría pertenecen los mandatos de interconexión que emite OSIPTEL.

\section{i. El acto administrativo}

El artículo $1^{\circ}$ del Texto Único Ordenado de la Ley del Procedimiento Administrativo General9 (la "LPAG") define el acto administrativo del siguiente modo:
"Son actos administrativos, las declaraciones de las entidades que, en el marco de normas de derecho público, están destinadas a producir efectos jurídicos sobre los intereses, obligaciones o derechos de los administrados dentro de una situación concreta".

De la definición anterior, es posible extraer los siguientes elementos constitutivos del acto administrativo:

(i) Se trata de una declaración procedente de una entidad de la Administración Pública. De conformidad con el Artículo I del Título Preliminar de la LPAG, esta definición incluye a todos los órganos del Poder Ejecutivo, gobiernos regionales y locales, y demás entidades con funciones administrativas, entre otros.

(ii) Debe ser emitida en el marco de normas de Derecho Público. Es decir, la calidad subjetiva del autor del acto (como entidad de la Administración Pública) no basta para que tal acto califique como acto administrativo. Debe tratarse de acto realizados en ejercicio de potestades públicas.

En términos generales, los actos de las entidades públicas cumplen con este requisito. La sustracción del Derecho Público debe ser, pues, expresa, mediante la aplicación de un marco legal específico y habilitante que le permita a las entidades actuar bajo el Derecho común10.

(iii) La declaración produce efectos jurídicos; es decir, tienen como objeto constituir, modificar, regular o extinguir relaciones jurídico-

\footnotetext{
Aprobado mediante Decreto Supremo 004-2019-JUS.

10 MORÓN, Juan Carlos. "Comentarios a la Ley del Procedimiento Administrativo General". Décimo Segunda edición. Lima: Gaceta Jurídica. 2017. pp. 188-189.
} 
administrativas11.

(iv) Tales efectos se producen sobre los intereses, obligaciones o derechos de los administrados. Es decir, los destinatarios directos de la decisión de la Administración Pública son terceros ajenos a la Administración.

(v) Finalmente, el acto administrativo se aplica en una situación concreta.

Para efectos de nuestro análisis, es importante comprender a qué se refiere el último de los elementos que caracterizan al acto administrativo, esto es, la exigencia de que el acto tenga efectos "dentro de una situación concreta".

Según señala Juan Carlos Morón, los efectos del acto administrativo son "concretos" en tanto se refieren a una materia y una situación jurídicoadministrativa específica12, predeterminada por las normas y previamente delimitada. El carácter "concreto" de los efectos del acto administrativo no se refiere al número destinatarios de tales efectos, sino a lo único e irrepetible de la situación.

El carácter concreto del acto administrativo es usualmente indicado como el principal factor diferenciador entre actos y reglamentos administrativos, en tanto estos, en contraposición con el acto administrativo, tienen una vocación de producción de efectos abstractos. La doctrina administrativa y la jurisprudencia han desarrollado ampliamente los elementos diferenciadores entre actos y reglamentos administrativos. Estos se describen continuación.

\section{ii. La norma administrativa o reglamento}

De acuerdo con la doctrina mayoritaria, las normas administrativas son declaraciones unilaterales de la Administración Pública que tienen efectos normativos generales y abstractos 13 y cuentan con las siguientes características14:

(i) Poseen fundamento constitucional. Esto quiere decir que la Administración no requiere de autorización legal para emitir una norma administrativa o reglamento; sin embargo, el contenido de dicha norma sí se encuentra limitado en forma y fondo por lo señalado en la ley.

(ii) La Administración Pública puede emitir normas administrativas unilateralmente. Sin embargo, para la Administración no es posible reglamentar aspectos reservados a la ley ni a normas legales que no corresponden ser aplicadas por la Administración Pública.

11 HUAPAYA, Ramón. "Propuesta de una nueva interpretación del concepto de acto administrativo contenido en la LPAG". En: Revista de Derecho Administrativo 9. 2010. p. 126.

12 MORÓN, Juan Carlos. "Comentarios a la Ley del Procedimiento Administrativo General". Décimo Segunda edición. Lima: Gaceta Jurídica. 2017. p. 188.

13 MORÓN, Juan Carlos. "Comentarios a la Ley del Procedimiento Administrativo General". Décimo Segunda edición. Lima: Gaceta Jurídica. 2017. p. 152.

14 Ibíd. p. 152. 
Ahora bien, nos interesa centrarnos en el carácter general y abstracto de las normas administrativas. De acuerdo con la doctrina, un acto tiene efectos generales cuando los destinatarios pueden ser todos o, por lo menos, una parte indeterminada de los sujetos bajo el ámbito de competencia del autor o emisor del acto15. Como contraposición, un acto de efectos especiales tiene como destinatario a una o varias personas identificadas de modo singular e inequívoco.

Por otro lado, se considera que un acto es abstracto cuando tiene por objeto regular supuestos de hecho o acciones definidos objetivamente y, por lo tanto, repetibles16. Los actos abstractos pueden ser aplicados cada vez que se configuran los supuestos de hecho o acciones objeto de dicho acto (por ejemplo, "operar una fábrica" o "ir por la carretera"). Como ya se ha adelantado, en contraposición con los actos abstractos, los actos concretos son aquéllos que tienen como objeto supuestos de hecho o acciones singulares e irrepetibles.

Ahora bien, la caracterización de los reglamentos administrativos como actos generales y abstractos muchas veces no permite diferenciar claramente los reglamentos administrativos de los actos administrativos. En efecto, surge la duda acerca de la calificación de aquellos actos especiales que regulan supuestos abstractos, así como de aquellos actos con efectos generales que tienen como supuesto un hecho concreto.

En el primer caso estamos frente a los reglamentos singulares, es decir, aquéllos que regulan un régimen general o abstracto para un grupo determinado de sujetos.

$\mathrm{Al}$ respecto, la doctrina señala lo siguiente17:

"La admisibilidad en abstracto de reglamentos singulares (esto es, de objeto o contenido abstractos, pero aplicables a un corto número de sujetos a determinados a priori o fácilmente determinables) parece difícil de discutir: no solo porque hay sectores del Derecho público en los que no cabe otra forma de normación (así, los reglamentos organizativos; o los reguladores de sectores económicos donde opera una sola empresa o un corto número de ellas), sino porque la singularidad del reglamento no supone una violación automática del principio constitucional de igualdad: puede suponerla, pero no la supone necesariamente, si se tiene en cuenta que este principio, del mismo modo que exige tratar de modo igual a los iguales, permite tratar desigualmente a los que se hallan en situaciones distintas (...)".

Así, si bien los reglamentos singulares tienen efectos particulares o especiales, lo que define que dicho acto sea un reglamento, es el carácter abstracto de las obligaciones que éste impone, pues es éste el que permite que el reglamento sea aplicado repetidamente y en situaciones diversas.

5 MARTIN, Richard. "Análisis de la función normativa de los Organismos Reguladores". En: Ius et Veritas, 24. 2002. p. 107.

16 Ibídem.

17 SANTAMARÍA, Juan Alfonso. "Fundamentos de Derecho Administrativo". Volumen I. Madrid: Centro de Estudios Ramón Areces. 1988. p. 725. Citado en: MARTIN, Richard. Op. Cit. p. 109. 
Por el otro lado, tenemos los actos referidos a situaciones concretas, pero que tienen efectos sobre un grupo indeterminado de personas, como, por ejemplo, una convocatoria a una licitación pública. Estamos frente a un acto que interesa a una pluralidad de destinatarios, formado por un número determinado o indeterminado de sujetos, pero que, dado el carácter concreto del acto, califica como acto administrativo de acuerdo con lo establecido en el artículo $1^{\circ}$ de la LPAG. La doctrina se ha pronunciado sobre estos actos reconociéndolos como "actos administrativos generales" 18.

De lo anterior se aprecia, entonces, que, de acuerdo con la doctrina, el factor fundamental que diferencia a la norma administrativa de los actos administrativos, es el carácter abstracto de la norma, es decir, que la aplicación de la norma no se agota se agota en actos ni hechos concretos y la aplicación del acto administrativo sí.

En lo que respecta a la jurisprudencia, los criterios y características descritas líneas arriba fueron considerados por la Sala de Derecho Constitucional y Social Permanente y Transitoria al emitir el Pleno Jurisdiccional Supremo en Materias Constitucional y Contencioso Administrativo, de fechas 2 y 10 de diciembre de 2015 (el "Pleno").

Dicho Pleno -que, de conformidad con lo dispuesto en la Ley Orgánica del Poder Judicial, debe ser invocado por los Magistrados de todas las instancias judiciales19estableció tres criterios para diferenciar los "reglamentos, normas administrativas y resoluciones y decretos de carácter general" -los cuales son objeto de control en los procesos de acción popular- de los actos administrativos. Estos criterios se pueden resumir del siguiente modo:

(i) Criterio de generalidad. Los reglamentos administrativos son impersonales; es decir, establecen consideraciones de alcance amplio para un conjunto indeterminado de destinatarios. A pesar de que el Pleno denomina el análisis de este elemento como un "análisis de abstracción", creemos que, en realidad, se trataría del elemento de generalidad descrito líneas arriba.

(ii) Criterio de consunción. Los reglamentos administrativos son susceptibles de una "infinidad de cumplimientos"; es decir, están destinados a ser aplicados o repetidos continuadamente en situaciones jurídicas futuras porque tienen vocación de permanencia en el sistema. Se trataría, pues, de la cualidad de un acto abstracto a la que nos hemos referido líneas arriba.

18 MORÓN, Juan Carlos. "Comentarios a la Ley del Procedimiento Administrativo General". Décimo Segunda edición. Lima: Gaceta Jurídica. 2017. p. 193.

19 Ello de conformidad con lo dispuesto en el artículo $22^{\circ}$ del Texto Único Ordenado de la Ley Orgánica del Poder Judicial (Decreto Supremo 017-93-JUS), las Ejecutorias que fijan principios jurisprudenciales emitidas por la Salas Especializadas de la Corte Suprema son de obligatorio cumplimiento en todas las instancias judiciales. 
(iii) Criterio ordinamental o de pertenencia al ordenamiento jurídico. Los reglamentos administrativos se incorporan al ordenamiento jurídico previamente existente, modificándolo, innovándolo, derogándolo o interpretándolo de modo permanente.

Como es posible notar, el Pleno también definió a los reglamentos administrativos como actos generales y abstractos. Sin embargo, consciente de la existencia de actos administrativos generales y de reglamentos particulares, el Pleno señaló que el criterio de generalidad "si bien útil, no resulta determinante para distinguir actos administrativos de normas reglamentarias".

En ese sentido -y teniendo en cuenta que el carácter ordinamental de los reglamentos deriva precisamente de su capacidad de trascender las situaciones concretas porque el acto en cuestión se incorpora al ordenamiento jurídico en lugar de ser una mera aplicación al caso concreto-, el Pleno habría establecido como criterio diferenciador fundamental entre actos y reglamentos administrativos el carácter abstracto -consuntivo- del reglamento. Solo aquellos actos destinados a ser aplicados en situaciones futuras ( $\mathrm{y}$ que, por tanto, se incorporen al ordenamiento) serán reglamentos administrativos. Los demás actos cuya aplicación se agota en situaciones concretas, son actos administrativos.

\section{iii. La naturaleza jurídica de los mandatos de interconexión}

Dicho lo anterior, corresponde analizar la figura de los mandatos de interconexión a la luz del marco legal, lo expuesto por la doctrina administrativa y lo dispuesto por el Pleno.

En primer lugar, es necesario tener claro qué es un mandato. Al respecto, no existe una definición legal de "mandato de interconexión" en el ordenamiento jurídico peruano. Sin embargo, existen diversas disposiciones referidas a los mandatos de interconexión que nos permiten ensayar una definición.

De acuerdo con el artículo $108^{\circ}$ del Reglamento de la Ley de Telecomunicaciones, el mandato de interconexión que dicta OSIPTEL contiene "las normas específicas" a las que se sujetará la relación de interconexión que se establezca entre las dos empresas operadoras.

Asimismo, el artículo $3^{\circ}$ de las Normas de Interconexión define a la interconexión como "el conjunto de acuerdos y reglas que tienen por objeto que los usuarios de los servicios de telecomunicaciones prestados por un operador puedan comunicarse con los usuarios de servicios de telecomunicaciones de la misma naturaleza, según la clasificación legal correspondiente, prestados por otro operador".

Adicionalmente, de conformidad con el artículo $51^{\circ}$ de las Normas de Interconexión, los concesionarios de telecomunicaciones pueden solicitar a OSIPTEL la emisión de un mandato de interconexión si, transcurrido un periodo 
de negociación de sesenta días calendario, las partes no hubiesen convenido los términos y condiciones de la relación de interconexión.

El contenido de los mandatos de interconexión, por su parte, se encuentra regulado en el artículo $52^{\circ}$ de las Normas de Interconexión. Esta disposición señala que los mandatos deben contener las normas específicas a las que se sujetará la relación de interconexión entre los operadores afectados, incluyendo: (i) las especificaciones técnicas de la interconexión; (ii) los cargos de acceso que generará; (iii) las fórmulas de ajuste que resulten aplicables; (iv) los mecanismos que garanticen el cumplimiento de obligaciones; $y$, (v) cualquier otro aspecto que OSIPTEL determine necesario.

Finalmente, como ya hemos indicado, de acuerdo con la Ley 27332, el Reglamento de OSIPTEL y las Normas de Interconexión, los mandatos de interconexión son emitidos por OSIPTEL en ejercicio de su función normativa.

A partir de las disposiciones antes citadas, puede extraerse que el mandato de interconexión es una resolución de OSIPTEL que establece las normas o reglas específicas -esto es, las condiciones técnicas, económicas y legales- que regirán la relación de interconexión entre dos empresas operadoras para que los usuarios de una de ellas puedan comunicarse con los usuarios de la otra.

Siguiendo los elementos definitorios de una norma administrativa o reglamento, aquellos comentados líneas arriba, analicemos primero si un mandato de interconexión califica como una norma.

(i) Criterio de generalidad: Conforme a este criterio, se debe analizar si nos encontramos frente a una disposición impersonal, es decir, que establece consideraciones de alcance amplio para un conjunto indeterminado de destinatarios.

El mandato de interconexión no constituye un acto de carácter impersonal porque tiene por finalidad establecer (o modificar, según sea el caso) una relación de interconexión particular que involucra únicamente a dos partes. Además, los términos y condiciones que OSIPTEL establece en el mandato son definidos considerando únicamente la situación y requerimientos de las dos empresas operadoras involucradas en la interconexión y de nadie más. Por ello, los mandatos, en principio, solo son aplicables a la relación de interconexión que regulan.

Prueba de lo anterior es que una empresa operadora puede ser parte de tantos mandatos de interconexión como relaciones de interconexión tenga establecidas con otros operadores. Si los mandatos tuvieran un alcance amplio para un conjunto indeterminado de destinarios, no sería necesario regular cada relación de interconexión a través de un mandato específico.

Es importante señalar que lo anterior no se altera por el hecho de que, de conformidad con las Normas de Interconexión, terceros operadores puedan 
invocar alguna condición más beneficiosa prevista en un mandato del que la empresa operadora que le provee el acceso o interconexión es parte, para aplicarla en su propio contrato o mandato de interconexión. Esta posibilidad no determina, sin embargo, que el mandato tenga efectos generales, ni mucho menos que esté destinado a un grupo indeterminado de agentes. Veamos.

El numeral 1 del artículo $30^{\circ}$ de las Normas de Interconexión señala:

“(...) los contratos y los mandatos de interconexión incluirán una cláusula que garantice que los cargos de interconexión y/o las condiciones económicas en general, se adecuarán cuando una de las partes, en una relación de interconexión con una tercera empresa operadora establecida, vía contrato o mandato de interconexión, aplique cargos de interconexión y/o condiciones económicas más favorables a las establecidas en su relación de interconexión". (énfasis agregado)

La citada norma exige que, tanto los contratos de interconexión como los mandatos, deban incluir una cláusula que disponga la adecuación de la relación jurídica creada por ese contrato o mandato a alguna(s) condicione(s) más favorable(s) que el titular de la infraestructura que provee el acceso o la interconexión, haya acordado con un tercero o hayan sido establecidas en un mandato del que dicho titular es parte.

Ahora bien, la obligación de incorporar tal compromiso a los contratos y mandatos de interconexión no implica de ningún modo que un mandato emitido respecto de "A y B" es imperativo ni automáticamente exigible para “C”, “ $\mathrm{D}$ ”, “E” o cualquier otro tercero. De hecho, el numeral 2 del artículo $30^{\circ}$ de las Normas de Interconexión afirma lo contrario, al establecer que "la adecuación requerirá una comunicación previa por parte de la empresa que se considere favorecida".

Pero, además, si se sostuviera que el mandato es una norma porque sus disposiciones pueden ser invocadas por un tercero para aplicarlas a su propia relación de interconexión, tendría que sostenerse lo mismo respecto de los contratos de interconexión. De acuerdo con el artículo $30^{\circ}$, un tercero también puede invocar una cláusula más beneficiosa de un contrato de interconexión que su contraparte ha suscrito, para exigir su aplicación a su propia relación de interconexión. Nadie podría sostener, sin embargo, que, por esta posibilidad, los contratos de interconexión en realidad no son contratos, sino normas.

Así pues, la aplicación del artículo $30^{\circ}$ de las Normas de Interconexión no sería un argumento válido para cuestionar el carácter singular de los mandatos de interconexión.

(ii) Criterio de consunción: Este criterio exige analizar si el acto tiene una finalidad que trasciende a la solución de una situación en concreto. En otras 
palabras, que está destinado a ser aplicado o repetido continuadamente en situaciones jurídicas futuras, sin que sus efectos se agoten con la situación que regula en particular.

$\mathrm{Al}$ respecto, es claro que los mandatos de interconexión no pueden ser automáticamente aplicados repetidamente a situaciones jurídicas futuras. Por el contrario, sus efectos se agotan con el establecimiento (o modificación) de la relación de interconexión, en los términos y condiciones que el mandato haya dispuesto.

Ahora bien, creemos que es importante distinguir entre un acto que "agota sus efectos" y un acto que "deja de surtir efectos". La diferencia parece evidente, pero merece la pena un comentario breve para entender por qué sostenemos que el mandato agota sus efectos con el establecimiento o modificación de la relación de interconexión.

El mandato, como cualquier acto administrativo, aprueba un determinado régimen legal aplicable a una situación, en este caso, una relación de interconexión. Establecer esa relación, regulando sus términos y condiciones (o, en su caso, modificar esa relación) es el propósito del mandato y este propósito se cumple, es decir, se agota o consume, con la emisión del mandato respectivo. Sus efectos, sin embargo, permanecerán hasta que le mandato pierda su vigencia. En efecto, el régimen de interconexión establecido o modificado permanecerá vigente en los términos que este mandato haya dispuesto.

Lo mismo ocurre, por ejemplo, con una resolución administrativa que otorga una autorización. Una vez emitida la resolución, su propósito (otorgar la autorización) se cumple y entonces agota sus efectos. Estos efectos, sin embargo, no se extinguen. La autorización continúa vigente hasta que el régimen que ésta haya aprobado cumpla su vigencia.

No queremos dejar de añadir que esta conclusión, en nuestra opinión, tampoco se ve alterada por el hecho de que terceros ajenos a la relación de interconexión puedan invocar alguna condición más beneficiosa para aplicarla a su propia relación de interconexión. Si bien ésta es una posibilidad que el marco legal ofrece a los terceros operadores ajenos a una relación de interconexión para fomentar una mayor competencia, su aplicación no es el propósito ni finalidad del mandato, la que se cumple -es decir, se agota-, con el establecimiento (o modificación) de la relación de interconexión que está en su objeto regular.

(iii) Criterio ordinamental: Conforme a este criterio, nos encontraremos ante una norma siempre y cuando el acto constituya una actuación que se integra al ordenamiento jurídico con la finalidad de modificarlo, innovarlo, derogarlo o interpretarlo con carácter permanente. Por el contrario, nos encontraremos ante un acto administrativo si lo que se pretende es aplicar una norma ya 
existente a un caso en concreto, sin que ello modifique la referida norma $u$ otra del ordenamiento jurídico.

Los mandatos de interconexión no tienen como vocación incorporarse al ordenamiento jurídico, sino solucionar posiciones contrapuestas entre dos empresas operadoras respecto de los términos y condiciones de una relación de interconexión.

Más aún, los mandatos aplican disposiciones legales prexistentes (principalmente previstas en las Normas de Interconexión) a una relación en particular y estas disposiciones no se ven afectadas con ni por la emisión de los mandatos.

A la luz de lo expuesto, nuestra opinión es que los mandatos de interconexión no cumplen con los criterios expuestos por la doctrina y por la jurisprudencia vinculante para calificar como una norma.

Es importante notar, adicionalmente, que los mandatos tampoco califican como reglamentos singulares. En efecto, tales reglamentos establecen un régimen abstracto para sujetos concretos y éste no es el caso de los mandatos de interconexión, los cuales, como hemos visto, no son abstractos porque su finalidad no trasciende la solución de una situación en concreto, esto es, el establecimiento o la modificación de la relación de interconexión.

Ahora bien, si procedemos con el mismo ejercicio respecto de la definición de acto administrativo provisto por el artículo $1^{\circ}$ de la $\mathrm{LPAG}_{20}$, tenemos que el mandato:

(i) Es una declaración emitida por una entidad que forma parte de la Administración Pública: OSIPTEL en su calidad de organismo regulador.

(ii) Es emitido en el marco de normas de derecho público, es decir, ejerciendo potestades públicas otorgadas a OSIPTEL por la Ley 27332, el Reglamento de OSIPTEL y las Normas de Interconexión.

(iii) Está destinado a producir efectos jurídicos sobre los interés, obligaciones y derechos de los administrados: las empresas operadoras;

(iv) Es aplicado a una situación concreta: la relación de interconexión específica entre dos operadores de telecomunicaciones.

Autores como Alejandro Moscol coinciden con esta posición. Así, éste señala21:

20 Que describe los actos administrativos como "declaraciones de las entidades públicas que, en el marco de normas de derecho público, están destinadas a producir efectos jurídicos sobre los intereses, obligaciones o derechos de los administrados dentro de una situación concreta".

21 MOSCOL, Alejandro. "Revisión de la figura del mandato de interconexión de redes y servicios públicos de telecomunicaciones desde la perspectiva del Derecho Administrativo". En: Revista de Derecho Administrativo 5. 2008. p. 97. 
"Ahora bien, un tema que debe ser analizado es si el mandato de interconexión califica como un acto administrativo y si sus cualidades se adecuan a la Ley del Procedimiento Administrativo General, Ley N 27444. Si bien el tema podría parecer evidente, existen ciertas características de este acto y que se describirán más adelante que justifican este análisis.

El artículo $1^{\circ}$ de la Ley del Procedimiento Administrativo General considera que son actos administrativos, las declaraciones de las entidades que, en el marco de normas de derecho público, están destinadas a producir efectos jurídicos sobre los intereses, obligaciones o derechos de los administrados.

El mandato de interconexión es una declaración del OSIPTEL, en su calidad de administración pública, y que se manifiesta a través de resoluciones de su órgano máximo, el Consejo Directivo. Esta declaración de la administración, que tiene carácter obligatorio, produce efectos jurídicos en las empresas operadoras titulares de las redes públicas a interconectarse." (énfasis agregado)

Otro elemento que evidencia que los mandatos de interconexión son actos administrativos es el hecho de que, como el propio OSIPTEL lo reconoce, los mandatos deben ser motivados en aplicación del artículo $6^{\circ}$ de la LPAG, mediante una relación concreta y directa de los hechos relevantes y la exposición de las razones jurídicas que justifican el mandato.

Esto es señalado por OSIPTEL en todas sus resoluciones de mandatos de interconexión, como, por ejemplo, en una recientemente emitida (Resolución 1232019-CD/OSIPTEL):

“(...) de conformidad con los antecedentes, análisis y conclusiones contenidos en el Informe Nº 00123- GPRC/2019 de la Gerencia de Políticas Regulatorias y Competencia, esta instancia hace suyos los fundamentos ahí expuestos y, acorde con el artículo 6, numeral 6.2, del TUO de la LPAG, dicho informe y el respectivo Mandato de Interconexión, constituyen parte integrante de la presente resolución y de su motivación; por lo que corresponde dictar el Mandato de Interconexión solicitado (...)"

Cabe añadir que la necesidad de motivación es una diferencia importante de los actos administrativos respecto de normas. En efecto, incluso en los casos en los cuales una norma tiene como origen una iniciativa privada (por ejemplo, a través del ejercicio del derecho de petición), la autoridad competente para emitir dicho acto normativo, no solo no está obligada a motivar su decisión (si decide o no acoger la petición); ni siquiera está obligada a ejercer función normativa para expedir el acto normativo que el particular haya puesto en consideración22.

Finalmente, el régimen de notificación de los mandatos también contribuye a demostrar que se trata de actos administrativos y no de normas. Si bien los

22 MOSCOL, Alejandro. MOSCOL, Alejandro. "Revisión de la figura del mandato de interconexión de redes y servicios públicos de telecomunicaciones desde la perspectiva del Derecho Administrativo". En: Revista de Derecho Administrativo 5. 2008. p. 97. 
mandatos se publican en el Diario Oficial El Peruano además de ser notificados a las partes, estos no entran en vigencia al día siguiente de su publicación, sino al día siguiente de su notificación a las partes involucradas en el mandato.

Esto se aprecia de la parte de resolutiva de los mandatos, los que señalan "El Mandato de Interconexión que se dicta mediante la presente resolución entrará en vigencia al día siguiente de su notificación" (el énfasis en negritas es agregado). Lo anterior es consistente con lo establecido en el artículo $50.6^{\circ}$ de las Normas de Interconexión que señala que OSIPTEL establece, en los mandatos de interconexión, la fecha en la cual estos entrarán en vigencia.

De lo anterior se aprecia, pues, que los mandatos de interconexión que emite OSIPTEL cumplen con los elementos constitutivos de un acto administrativo y, por lo tanto, podemos afirmar que el mandato es un acto administrativo y no una norma.

Ahora bien, ¿la naturaleza de mandato como acto administrativo cambia por el hecho de que, conforme al marco legal, OSIPTEL los emite en ejercicio de su función normativa? Nuestra opinión es que no. Que los mandatos sean emitidos por OSIPTEL en ejercicio de la función normativa, no determina que estos tengan la naturaleza jurídica de una norma.

La naturaleza jurídica de un acto es la que deriva de las características de ese acto, al margen de la denominación de la función que ejerza la autoridad cuando lo expide. Lo que interesa analizar, para determinar la naturaleza de un acto, es, en palabras del Tribunal Constitucional "el sustento material al que obedece" 23, no las circunstancias -normativas o no- en las que dicho acto se emite, menos aún la forma cómo la norma lo denomina.

Esta es una conclusión que nos permitimos extrapolar del principio jurídico de primacía de la realidad. Este principio otorga prioridad a los hechos, es decir a lo que efectivamente ocurre en la realidad, sobre las formas o apariencias de un acto. Al respecto, la doctrina expresa que el principio de primacía de la realidad exige que, en caso de discordancia entre lo que ocurre en la práctica y lo que surge de documentos o acuerdos, se acuerde preferencia a lo primero, es decir a lo que ocurre en el terreno de los hechos 24.

El principio de primacía de la realidad, si bien utilizado principalmente en el Derecho Laboral y Civil, no es una figura que le pertenezca exclusivamente a estas ramas. Como señala Adrián Oscar Morea25, no tiene como finalidad esencial caracterizar situaciones que sean propias de estas ramas. Este principio, como lo indica el citado autor, deriva de la Teoría General del Derecho como postulación

23 Sentencia expedida en el Exp. 04870-2007-PA/TC.

24 RODRIGUEZ, Pla."Los principios del Derecho Laboral", Buenos Aires, Depalma, 1978, p. 243.

25 MOREA, Adrián Oscar. "Radiografía del principio de primacía de la realidad." En: Sistema Argentino de Información Jurídica. 2014. Consulta realizada el día 30 de diciembre de 2019. Disponible en: http://www.saij.gob.ar/doctrina/dacf140002-morearadiografia_principio_primacia_realidad.htm. 
de que la verdad material de un acto prima sobre su forma o sobre el acuerdo y, como tal, es una directiva esencial para autoridades, jueves y administrados.

En nuestra opinión, la aplicación del principio de primacía de la realidad permite concluir que la denominación "función normativa" de la Ley 27732 otorga a la facultad de OSIPTEL para emitir mandatos, no determina la naturaleza jurídica de los mandatos de interconexión, por cuanto lo que uno debe analizar para definir esta naturaleza son las características reales del mandato y los efectos que produce en la esfera jurídica de los administrados. No el título que el marco legal ha brindado a la función que ejerce su autor al emitirlo.

Como hemos desarrollado, los mandatos de interconexión cumplen con todos los elementos constitutivos de un acto administrativo y, por lo tanto, esta naturaleza no varía por el hecho de que OSIPTEL ejerza función normativa al expedirlos.

\section{La impugnación de los mandatos y la actual posición de OSIPTEL}

El inciso 1 del artículo $137^{\circ}$ de las Normas de Interconexión señala que los mandatos son emitidos por el Consejo Directivo de OSIPTEL. Éste es el órgano máximo de dirección de OSIPTEL, por lo que la impugnación de los mandatos de interconexión está sujeta a lo previsto en el artículo $219^{\circ}$ de la LPAG26; esto es, a la interposición de un recurso de reconsideración, por tratarse de un acto administrativo que es emitido por un órgano que es instancia única.

La resolución que emite el Consejo Directivo resolviendo el recurso de reconsideración agota la vía administrativa de impugnación del mandato. Por lo tanto, la impugnación de dicha resolución corresponde ser tramitada en la vía contencioso administrativa, conforme a lo dispuesto en la Ley 27584, Ley que regula el Proceso Contencioso Administrativo.

Ahora bien, OSIPTEL siempre ha dado trámite y ha resuelto las impugnaciones que presentan las operadoras contra los mandatos de interconexión como recursos de reconsideración y entendemos que esta práctica, afortunadamente, se mantiene.

Sin embargo, no ha ocurrido lo mismo con la impugnación judicial de los mandatos. En efecto, hemos podido advertir que, recientemente, OSIPTEL ha variado radicalmente su posición respecto de la posibilidad de impugnar los mandatos de interconexión (o, mejor dicho, las resoluciones que resuelven los recursos de reconsideración contra los mandatos de interconexión) en un proceso contencioso administrativo, para pasar a sostener que la impugnación de los mandatos de interconexión (y de compartición) correspondería ser tramitada en un proceso de acción popular por cuanto los mandatos serían normas y no actos

26 “Artículo 219.- Recurso de reconsideración El recurso de reconsideración se interpondrá ante el mismo órgano que dictó el primer acto que es materia de la impugnación y deberá sustentarse en nueva prueba. En los casos de actos administrativos emitidos por órganos que constituyen única instancia no se requiere nueva prueba. Este recurso es opcional y su no interposición no impide el ejercicio del recurso de apelación". 
administrativos. El sustento de OSIPTEL para sostener que los mandatos son normas es el comentado artículo $3^{\circ}$ de la Ley 27332 y demás disposiciones legales y reglamentarias que señalan que los mandatos son emitidos por los organismos reguladores "en ejercicio de la función normativa".

En nuestra opinión, OSIPTEL se equivoca. Ya hemos señalado que los mandatos son actos administrativos y no normas y que el hecho de que OSIPTEL ejerza una función normativa al emitirlos, no altera su naturaleza, la cual depende de las características del acto y no de la habilitación legal que tiene su autor o emisor para crearlo.

Pero, adicionalmente, es importante considerar que existen múltiples casos en los cuales los operadores de telecomunicaciones han impugnado mandatos emitidos por OSIPTEL a través de procesos contencioso administrativos, en los cuales este Regulador se ha sometido pacíficamente a la competencia de los jueces, entendiendo que los administrados tienen derecho a impugnar sus mandatos a través de dicha vía.

De esta manera, en nuestra opinión, lo señalado por OSIPTEL no solo es equivocado desde el punto de vista de la naturaleza jurídica de los mandatos de interconexión o compartición (que son actos administrativos y no normas), sino desde la perspectiva del Principio de Predictibilidad o Confianza Legítima y Buena Fe Procedimental que se encuentran recogidos en la LPAG y que guían toda actuación de OSIPTEL.

Asimismo, otro error que comete OSIPTEL consiste en señalar que los mandatos de interconexión corresponden ser impugnados a través del proceso constitucional de acción popular. El artículo $76^{\circ} 27$ del Código Procesal Constitucional es muy claro en señalar que la acción popular solo cabe respecto de normas de carácter general y, como hemos comentado, los mandatos de interconexión no califican como actos de carácter general. Más aún, siguiendo la argumentación de OSIPTEL, la norma que este organismo invoca para sostener que los mandatos constituyen normas, se referiría al mandato como "otras normas de carácter particular" 28 y no general.

Entonces, si los mandatos legalmente no pueden ser cuestionados a través de una acción popular, y, para OSIPTEL, los mandatos no son susceptibles de ser impugnados en la vía contencioso administrativa, ¿cuál es la vía que las empresas

27 “Artículo 76.- Procedencia de la demanda de acción popular

La demanda de acción popular procede contra los reglamentos, normas administrativas y resoluciones de carácter general, cualquiera que sea la autoridad de la que emanen, siempre que infrinjan la Constitución o la ley, o cuando no hayan sido expedidas o publicadas en la forma prescrita por la Constitución o la ley, según el caso."

28 Nos referimos al artículo $3^{\circ}$ de la Ley 27332, que define la función normativa como aquella que “comprende la facultad de dictar en el ámbito y en materia de sus respectivas competencias, los reglamentos, normas que regulen los procedimientos a su cargo, otras de carácter general y mandatos $\mathrm{u}$ otras normas de carácter particular referidas a intereses, obligaciones o derechos de las entidades o actividades supervisadas o de sus usuarios". 
operadoras tendrían que iniciar para impugnar los mandatos? ¿Ninguna? OSIPTEL incurre, pues, en un grave error que no solo supone ignorar los criterios vinculantes que han sido desarrollados por los Jueces Supremos en el Pleno comentado en este artículo, sino que implicar dejar en absoluta indefensión a las empresas operadoras quienes, de no estar de acuerdo con lo resuelto por OSIPTEL en la vía administrativa (es decir, en el mandato de interconexión), no podrían cuestionar su decisión en ningún otro fuero.

Recordemos, apreciado lector, que los mandatos de interconexión no son un instrumento menor de regulación. Los mandatos imponen obligaciones económicas a los operadores de telecomunicaciones para promover la competencia y estas obligaciones tienen una enorme incidencia en su modelo de negocio y en la forma cómo operan en el mercado. Por eso, que se impida el cuestionamiento de los mandatos en la vía judicial a través de un proceso contencioso administrativo (vía legal que corresponde), es un atropello a los derechos de las empresas operadoras que OSIPTEL no debería permitir, mucho menos participar de ella.

Finalmente, es oportuno señalar que, afortunadamente, existen casos de procesos contenciosos administrativos en los cuales los argumentos de OSIPTEL han sido desestimados por los jueces, quienes han sido muy claros en señalar que los mandatos constituyen actos administrativos y, por lo tanto, su cuestionamiento en la vía judicial corresponde ser tramitado a través del proceso contencioso administrativo.

\section{Conclusiones}

La naturaleza jurídica de los mandatos de interconexión es clara. Se trata de actos administrativos y no de normas y esta calificación no se ve alterada por el hecho de que OSIPTEL emite los mandatos en ejercicio de la función normativa que el marco legal le ha atribuido.

Hasta hace un tiempo, OSIPTEL nunca había cuestionado la calificación de los mandatos como actos administrativos. Menos aún había sostenido que estos constituyen normas. La nueva posición de OSIPTEL es manifiestamente equivocada y es importante que este error sea corregido a efectos de que los mandatos de interconexión sean aplicados, por OSIPTEL y las empresas operadoras, con el alcance, efectos y consecuencias que corresponden a un acto administrativo.

Y la consecuencia que más nos preocupa en este momento es la imposibilidad en la que actualmente se encuentran las empresas operadoras para cuestionar los mandatos de OSIPTEL en la vía judicial porque, de acuerdo con el Regulador, los mandatos no corresponden ser cuestionados en la vía contencioso administrativa, sino en un proceso de acción popular (donde, como hemos visto, legalmente es imposible cuestionar un mandato porque no califica como una norma de carácter general). Esta limitación, evidentemente, supone una afectación muy al derecho 
de defensa y al debido procedimiento de las empresas operadoras que confiamos OSIPTEL pronto corregirá.

El mandato de interconexión es una pieza que ha jugado un rol fundamental en la promoción de competencia en el mercado de los servicios de telecomunicaciones y que OSIPTEL, durante mucho tiempo, ha expedido cumpliendo con todas las exigencias que caracterizan a un acto administrativo, principalmente aquéllas destinadas a resguardar los derechos de las empresas operadoras. Confiamos en que lo volverá a hacer. 